\title{
The influence of the applied mechanical vibration during welding on the residual stress and the fatigue crack growth rate of AA-5083 aluminum alloy
}

\author{
R. Tamasgavabari ${ }^{1}$, A. R. Ebrahimi ${ }^{2}$, S. M. Abbasi ${ }^{1}$ \\ ${ }^{1}$ Faculty of Material \& Manufacturing Technologies, Malek Ashtar University of Technology, Tehran, Iran \\ ${ }^{2}$ Department of Materials and Metallurgical Engineering, Amirkabir University of Technology, Tehran, Iran
}

Received 28 November 2019, received in revised form 10 April 2020, accepted 23 April 2020

\begin{abstract}
Vibratory weld conditioning (VWC) was performed on the AA-5083 aluminum alloy specimens while they were welded with gas metal arc welding (GMAW). The variables in this study were vibration forces range from 400-3150 N and vibration frequency of 50-90 Hz. Microstructure, residual stress, and fatigue crack growth behavior of the welded samples were examined. Fracture analysis was also undertaken after the fatigue crack growth test using a scanning electron microscope (SEM). The results show that compared to the no-vibration welded sample, with increasing vibration forces, the columnar structure was replaced by equiaxed grains, and the area fraction of equiaxed grains increased to $75 \%$. In contrast to the sample welded without vibration, residual stress decreased while vibration was applied during welding. On the other hand, the application of mechanical vibration during welding, at each given frequency of 50,75, and $90 \mathrm{~Hz}$ caused residual stress decrement of about 36, 38, and $44 \%$. At low $\Delta K$ values, the crack growth rate is low in all welded specimens and is approximately similar to the crack growth rate of the no-vibration welded specimen. Tensile residual stress is an effective reason that caused the crack growth rate of the material to increase.
\end{abstract}

K e y w or d s: vibratory weld conditioning (VWC), equiaxed grain, residual stress, 5083 aluminum alloy, fatigue crack growth

\section{Introduction}

Aluminum alloys have been selected as a candidate for structural materials due to the attractive properties, including light weight, moderate strength, good corrosion resistance, and proven weldability [1-3]. AA-5083 is a non-heat-treatable aluminum alloy, mainly used in the main building of ocean vessels $[4-6]$. The most significant challenge for using aluminum is the loss of strength when fusion welding is involved. Besides, due to fusion welding, coarse dendrites are formed in the fusion zone. Also, because of the non-homogeneous thermal gradient, residual stress can be formed in the welded components [7-9]. Residual stress could reduce crack initiation time [10, 11], tend to decrease fatigue life, and stress corrosion cracking (SCC) [12-14].

To eliminate the residual stress, some of the older techniques such as shot peening, solid-state welding (e.g., friction stir welding), and heat treatment have been applied [15-17]. The standard method used for residual stress reduction is thermal stress relief by heating the structure to a relatively high temperature. At the high temperature, the creep strength of the material is low. Creep relaxes the elastic strains to values much below that characteristic of the hightemperature yield stress $[18,19]$.

Vibratory stress relief (VSR) is a post-weld treatment in which vibration force is applied to the welded structure. The application of vibration during the welding process (called vibratory weld conditioning $(\mathrm{VWC})$ ) is a process derived from VSR. VWC is a process in which vibration force is applied with a sufficient amplitude during the welding of the components. Application of vibration during welding is beneficial in such ways including residual stress decrement,

*Corresponding author: tel.: +98 21 64542979; e-mail address: arebrahimi@aut.ac.ir 
Table 1. Chemical composition of the samples and the welding electrode (wt.\%)

\begin{tabular}{lccccccccc}
\hline Element & $\mathrm{Si}$ & $\mathrm{Fe}$ & $\mathrm{Cu}$ & $\mathrm{Mn}$ & $\mathrm{Mg}$ & $\mathrm{Cr}$ & $\mathrm{Ti}$ & $\mathrm{Zn}$ & $\mathrm{Al}$ \\
\hline AA-508 & 30.32 & 0.29 & 0.44 & 0.88 & 4.73 & 0.09 & 0.02 & 0.22 & Base \\
Al518 & 30.41 & 0.38 & 0.11 & 0.75 & 4.78 & 0.11 & 0.15 & 0.25 & \\
\hline
\end{tabular}
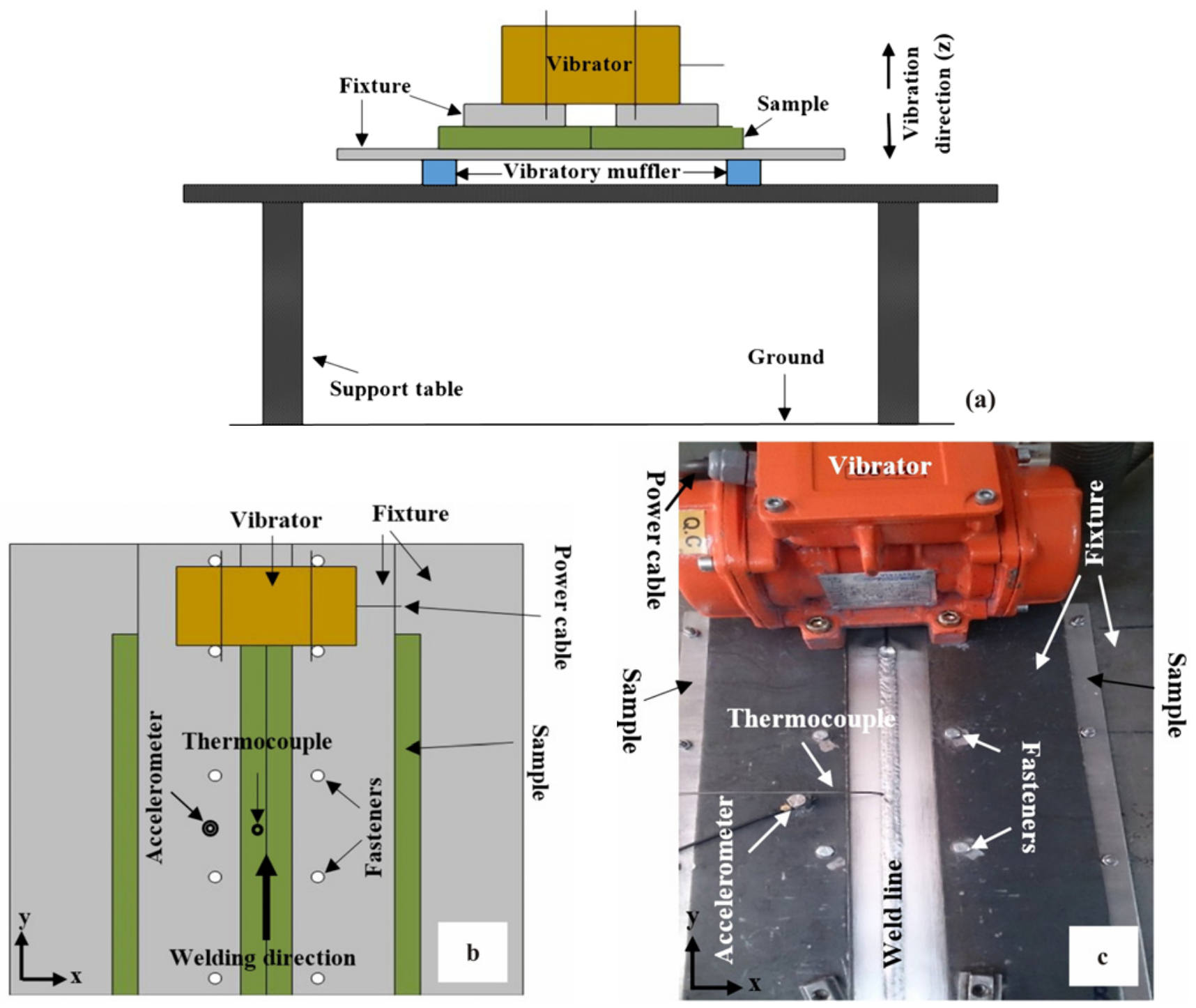

Fig. 1. Welding structure design: (a) side view, (b) top view, and (c) welding structure actual assembly [32].

heat transfer rate acceleration, and reduction of the thermal gradient in the weld pool from the weld center to the weld edge, so constitutional supercooling increases. Finally, the growth rate diminished, then smaller grains can be generated $[9,10]$. In contrast to the post-weld heat treatment, which is a high-energy consuming process and does not apply to the large structures, vibratory weld conditioning is a process with low energy consumption that reduces production costs. It is also a process with no air pollution generation [20, 21].

VWC improves the mechanical properties of welded joints, which is mainly due to the effective grain refinement and the increased resistance of the weld to crack initiation. Application of vibration during welding causes nondendritic fine equiaxed grains to generate. The nondendritic structure is advantageous, mainly because of higher plasticity and a notably higher crack resistance [22]. Campbell [23] has reported the effect of mechanical vibration, which was applied during the solidification process of cast alloys, on the grain refinements.

Several research studies have been conducted on the influence of vibratory weld conditioning on resid- 
Table 2. GMAW parameters of AA-5083-H321 aluminum alloy samples

\begin{tabular}{ccccccc}
\hline $\begin{array}{c}\text { Welding } \\
\text { position }\end{array}$ & $\begin{array}{c}\text { Root gap } \\
(\mathrm{mm})\end{array}$ & $\begin{array}{c}\text { Electrode } \\
\text { diameter }(\mathrm{mm})\end{array}$ & $\begin{array}{c}\text { Arc current } \\
(\mathrm{A})\end{array}$ & $\begin{array}{c}\text { Arc voltage } \\
(\mathrm{V})\end{array}$ & $\begin{array}{c}\text { Welding speed } \\
\left(\mathrm{cm} \mathrm{min}^{-1}\right)\end{array}$ & $\begin{array}{c}\text { Gas flow } \\
\left.(\mathrm{L} \mathrm{min})^{-1}\right)\end{array}$ \\
\hline Flat & 1.2 & 1.2 & 166 & 22 & 45 & 14 \\
\hline
\end{tabular}

Table 3. Vibration parameters of welding structure

\begin{tabular}{cccc}
\hline Sample No. & $\begin{array}{c}\text { Frequency } \\
(\mathrm{Hz})\end{array}$ & $\begin{array}{c}\text { Vibration force } \\
(\mathrm{N})\end{array}$ & $\begin{array}{c}\text { Physical displacement } \\
\text { of welding structure }(\mu \mathrm{m})\end{array}$ \\
\hline 1 & 50 & 400 & 130 \\
2 & & 750 & 300 \\
3 & 75 & 1000 & 350 \\
\hline 4 & & 850 & 65 \\
5 & & 1650 & 115 \\
6 & 90 & 2200 & 20 \\
\hline 7 & & 1250 & 80 \\
9 & & 2350 & 125 \\
\hline 10 & & 3150 & \\
\hline
\end{tabular}

ual stress reduction [24-26]. Limited investigations were carried out about the effect of vibratory weld conditioning on microstructure and the tensile properties [27-30]. Moreover, variations of the yield strength in terms of welded samples grain size, due to vibratory weld conditioning are reported in [31].

Literature has discussed the vibration effect on the welded parts. Still, it was not clearly explained about the impact of vibration force and vibration frequency on the microstructure and the mechanical properties of the welded parts, and the relation between them, by attention to the vibrational behavior of the structure. Also, the vibration analysis of the welded structure was not considered. Most of the fusion welding methods require post-weld treatments due to high heat input, grain growth, residual stress, and reduction of mechanical properties. In this study, following the background of using mechanical vibration to improve the final microstructure and the mechanical properties of various types of weldments, vibration force was applied during welding. The AA-5083-H321 aluminum alloy specimens were welded by GMAW, in the buttjoint configuration while being vibrated, and a study on the influence of the applied mechanical vibration during welding of the samples on the microstructure, residual stress, and crack growth rate has been carried out.

\section{Experimental procedure}

The welding sample is a $5 \mathrm{~mm}$ thick AA-5083-H321 aluminum alloy plate, which is cut into $400 \times 150 \mathrm{~mm}^{2}$. Then, the samples were beveled to a $30^{\circ}$ of each plate to provide a $60^{\circ} \mathrm{V}$-butt joint configuration. The chemical composition of the AA-5083-H321 aluminum alloy sheet and the welding electrode is shown in Table 1.

The welding samples were fixed into three sheets of steel as the welding fixture. The lower part was $500 \times 500 \times 3 \mathrm{~mm}^{3}$, and two pieces of sheets measuring $500 \times 100 \times 5 \mathrm{~mm}^{3}$ were used as the upper fixtures (Fig. 1 [32]). The welding structure was located on a vibration-isolated base to eliminate excessive vibration from the ground. The samples were carefully cleaned using acetone before welding. After chemical cleaning, the aluminum oxide layer was removed by a stainless steel brush. Finally, the samples were welded according to the welding parameters listed in Table 2 .

To study the effect of vibration force and vibration frequency on the microstructure, residual stress, and crack growth rate of the welded AA-5083-H321 aluminum alloy samples, ten series of the samples were welded in butt-joint configuration, in which nine samples were welded while being vibrated and one sample without vibration. The variables used in this study were vibration force ranged from 400-3150 N applied with an $\mathrm{AC}$ vibrating motor, and vibration frequency of 50,75 , and $90 \mathrm{~Hz}$. Table 3 summarizes the vibration parameters entered into the welding structure during the welding process, paying attention to the vibration response of the welding structure. To record the vibration parameters of the structure such as the physical displacement of the structure under the influence of vibration, a CA-YD-11814 (SINOCERA) accelerome- 

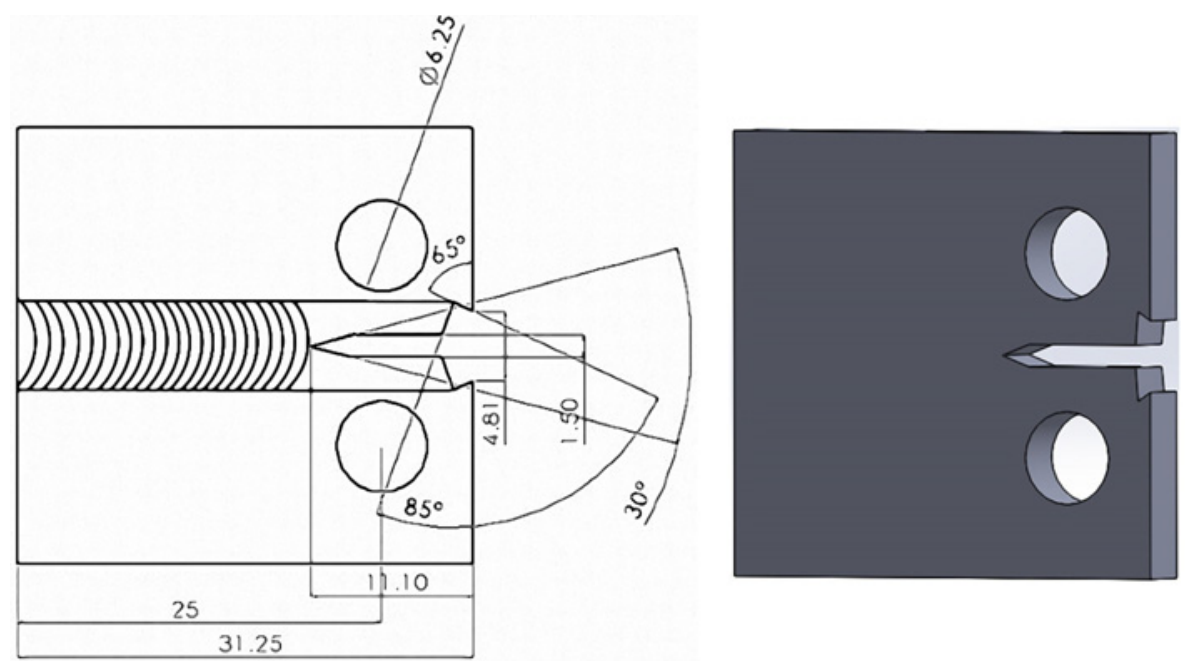

Fig. 2. Fatigue crack growth test sample drawing (dimensions in $\mathrm{mm}$ ).

Table 4. Residual stress measurement parameters using $\mathrm{XRD}$

\begin{tabular}{lc}
\hline Radiation & $\mathrm{Cu} \mathrm{K} \alpha 1.54645^{\circ} \mathrm{A}$ \\
$2 \theta_{\{422\}}$ & $80^{\circ}-150^{\circ}$ \\
$\psi$ & $0^{\circ}, 10^{\circ}, 20^{\circ}, 30^{\circ}, 40^{\circ}$, and $50^{\circ}$ \\
Tube voltage & $40 \mathrm{kV}$ \\
Tube current & $37 \mathrm{~mA}$ \\
Curve fitting & Gauss function \\
\hline
\end{tabular}

ter sensor was mounted on the welding structure (see Fig. 1c).

After welding, all samples were thoroughly inspected by radiographic non-destructive testing (RT). Then, they were cut perpendicular to the welding direction for metallographic examination and crack growth tests via an electro-discharge cutting machine (EDM). To study the area fraction of the equiaxed grain, the cross-sections of the welded samples were polished followed by treating with a reagent mixing $50 \mathrm{ml}\left(1 \mathrm{ml} \mathrm{H}_{2} \mathrm{O}+6 \mathrm{ml} \mathrm{HNO}_{3}+1 \mathrm{ml} \mathrm{HF}+12 \mathrm{ml}\right.$ $\mathrm{HCl})+25 \mathrm{ml} \mathrm{H} 2 \mathrm{O}+40 \mathrm{ml} \mathrm{HNO}_{3}+12 \mathrm{~g} \mathrm{CrO} 3$ at room temperature. Then they were investigated using the ZEISS (Axioplan 2 Imaging) optical microscope.

Residual stress was measurement conducted by a scanning X-ray diffractometer (Inel equinox 6000) with $\mathrm{Cu} \mathrm{K} \alpha$, according to the $\sin ^{2} \psi$ method per BS EN 15305 [33]. Also, the data figured out in real time. The type of the residual stress measured adjacent to the weld line was longitudinal, represented the residual stress at the surface layer of the material. The XRD parameters are in Table 4.

Besides, a fatigue crack growth test was carried out on a computer-controlled servo-hydraulic INSTRON 8516 testing machine to study the fatigue behavior of welded samples at room temperature. For this pur- pose, the samples were prepared according to ASTM E647 [34], schematically shown in Fig. 2. Also, an extensometer was used precisely determining the nucleation and growth of the crack under the cyclic load. The experimental parameters of the fatigue crack growth test were the maximum load of $2700 \mathrm{~N}$, and the minimum load of $400 \mathrm{~N}$. The load ratio, $R$ $\left(P_{\min } / P_{\max }\right)$ was 0.148 , and the frequency of the loading cycles was $5 \mathrm{~Hz}$. After the fatigue crack growth test, the fracture surfaces were studied using SEM (Leo $1450 \mathrm{VP}$ ).

\section{Results and discussion}

\subsection{Microstructural observation}

Figure 3 shows the effect of mechanical vibration on the microstructure of the welded sample. The sample welded with conventional GMAW includes columnar grains in the fusion line, but the coarse equiaxed grains were produced in the weld center. However, the columnar grains disappeared due to the influence of the applied vibration. Equiaxed grains originated from the fragmented dendrites, in which the mechanical vibration of the weld pool promotes the dendrite fragmentation, and weld metal convection carries the fragmented dendrites, disperses them from the region near the fusion line to the weld center, makes new nucleation sites resulting fine equiaxed grains generation. This phenomenon leads to grain refinement and the disappearance of coarse grains in the center of the weld. However, the grain size in the vibration-assisted welded sample is finer than that in the conventional GMAW welded sample.

From the consideration mentioned above, when vibration frequency was varied from $50-90 \mathrm{~Hz}$ and the vibration force was ranged from $400-3150 \mathrm{~N}$, the area 

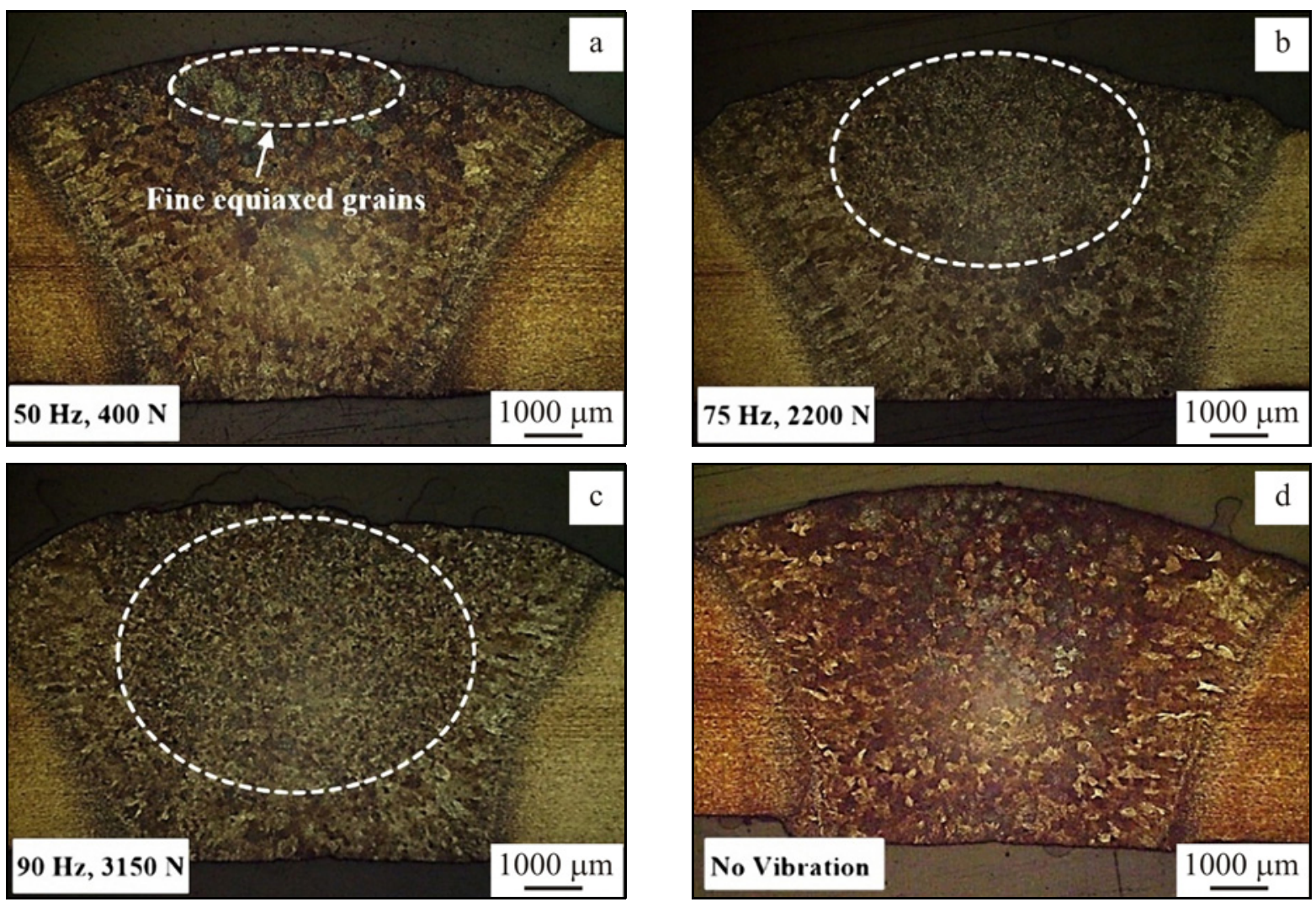

Fig. 3. The optical micrographs of the welded samples: (a) $50 \mathrm{~Hz}, 400 \mathrm{~N}$, (b) $75 \mathrm{~Hz}, 2200 \mathrm{~N}$, (c) $90 \mathrm{~Hz}, 3150 \mathrm{~N}$, and (d) no vibration.

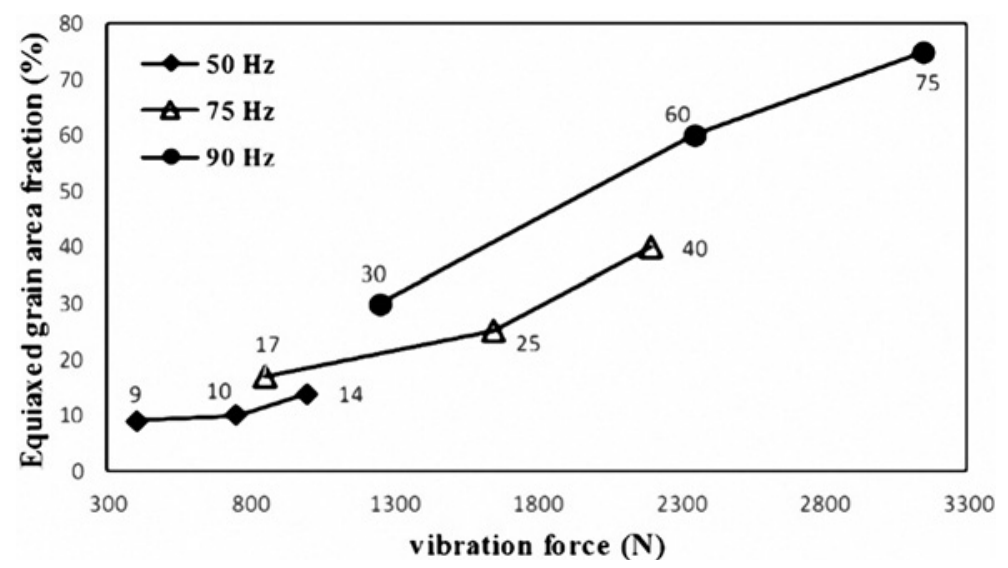

Fig. 4. The fine equiaxed grains zone area fraction of the weld samples.

fraction of equiaxed fine grains (was calculated by dividing the area of refined grains by that across the entire weld) was increased from 9-75\%. On the other hand, while a higher vibration force was applied, smaller grains were produced in the weld metal.

Figure 4 depicts the area fraction of the equiaxed fine grains of the welded samples with respect to the vibration force. At identical welding conditions, the application of vibration during welding led to grain refinement, including a reduction in grain size and the increment of the area fraction of equiaxed grains. Sev- eral studies based on the grain refinement of $\mathrm{Al}$ alloys in the welded joints have been carried out extensively [35-37]. The ways in which grains are refined by mechanical vibration may include dendrite fragmentation, grain detachment, and heterogeneous nucleation. The process mentioned above could occur due to the fragmentation of the dendrite tips in the mushy zone due to weld pool convection, detaching of loosely held grains in the partial melting zone in the temperature between $T_{\text {Liquidus }}$ and $T_{\text {Eutectic }}$, and acting as a non-homogeneous nucleus of external par- 
Table 5. XRD data for the welding sample, welded with a frequency of $75 \mathrm{~Hz}$ and vibration force of $1650 \mathrm{~N}$

\begin{tabular}{ccccccc}
\hline$\psi$ & 0 & 10 & 20 & 30 & 40 & 50 \\
\hline $2 \theta$ & 136.11 & 136.282 & 136.249 & 136.374 & 136.346 & 136.553 \\
$d$ & 0.82919 & 0.82979 & 0.82970 & 0.83007 & 0.82997 & 0.83046 \\
$\varepsilon$ & -0.00098 & -0.00025 & -0.00036 & 0.000084 & -0.00036 & 0.00055 \\
\hline
\end{tabular}

ticles presented in the weld pool, respectively. Additionally, the bending stress interred into the welding structure could cause the dendrite arms to break down, crushed into smaller parts. With increasing the vibration force, the bending stress, which was interred into the molten metal, increased significantly. Meanwhile, while vibration was applied, weld pool convection increased. Therefore, fragmented dendrites and detached grains were carried into the bulk weld pool. Detached grains like fragmented dendrites can act as the nucleus if they can survive in the weld pool temperature. According to the nucleation theory, if atoms in a liquid metal are brought together and form solid nuclei that are larger than the critical size to overcome the critical energy barrier, they can survive, grow, and act as heterogeneous nucleation sites [38]. From literature, other grain refinement processes due to the application of mechanical vibration are turbulent melt flow around dendrite arms and showering due to the impingement of detached dendrites [23]. Surface grain refinement also could occur using a cooling gas entered into the surface of the molten pool either by instant temperature reduction or by removing heat. The major effect of turbulence caused by vibration is local fluctuation in the molten metal temperature around dendrite arms. The temperature fluctuations are so strong that the melting conditions of dendrite arms are provided [38].

\subsection{Residual stress measurement}

Residual stresses are those stresses that would exist in a body if all external loads were removed. Attention to residual stress is mainly due to its role in fatigue, fractures, and stress corrosion cracking (SCC) [12, 13, 39]. Since 1930, the residual stress in welding and its effect on welding performance have been studied [40]. Residual stresses, if compressive, increase fatigue life, reduce SCC and hydrogen embrittlement [41].

The XRD method was used to measure the residual stress of the samples. The basis of this method is to change the crystal lattice due to the stress causing the displacement of the spectra. If the metal is plastically deformed, the crystal lattice usually changes, in which the distance of each crystal plane (hkl) varies from one grain to a neighbor grain. This uneven microstrain leads to the diffraction pattern to broaden. The residual stress in metals results in the displacement and broadening of the diffraction pattern, not only due to the differentiation of crystal plane spacing from one grain to another one but also its amount in the metal, which is plastically deformed, is varied from the undeformed one.

Using XRD, the strain in the crystal lattice measured, and the associated residual stress can be determined based on the elastic distortion of the appropriate crystal lattice plane. Many metallic specimens strongly absorb X-rays and because of this phenomenon, the intensity of the incident beam greatly reduced in a very short distance below the surface. Consequently, the majority of the diffracted beam originated from a thin surface layer, and hence, the residual stress measurements correspond only to the surface layer of the material. The XRD stress measurement is taken with the $\sin ^{2} \psi$ method, according to Eq. (1):

$$
\sigma_{\psi}=\left(\frac{E}{1+v}\right)_{(\mathrm{hkl})} \frac{1}{d_{0}}\left(\frac{\partial d_{\Phi \psi}}{\partial \sin ^{2} \psi}\right)
$$

where $d_{\Phi \psi}$ is the spacing between the lattice planes measured in the direction, which is defined by $\Phi$ and $\psi$. $E$ is Young's modulus, and $v$ is the Poisson ratio. Furthermore, the network strain $(\varepsilon)$ is expressed according to Eq. (2):

$$
\varepsilon=\left(\frac{\partial d_{\Phi \psi}}{\partial d_{0}}\right)=\ln \left(\frac{d_{\Phi \psi}}{d_{0}}\right)
$$

In an undeformed material, the distance between the crystal planes is $d_{0}$, and the spectra position being at $2 \theta$ angles. It differs from $d_{\Phi \psi}$, due to residual stress [33]. Table 5 shows the XRD data for the welding sample, which was welded with a frequency of $75 \mathrm{~Hz}$ and the vibration force of $1650 \mathrm{~N}$.

Figure 5 shows the relationship between the network strain $(\varepsilon)$ of the sample and the change of $\sin ^{2} \psi$. By attention to the text mentioned above, the measured residual stresses of the samples are shown in Fig. 6.

The residual stress of the non-vibration welded sample was $170 \mathrm{MPa}$, whereas by applying vibration force, the residual stress decreased to the lower amounts. In other words, since the vibration force increased from $400-1000 \mathrm{~N}$, at a given frequency of $50 \mathrm{~Hz}$, the residual stress changed from 109-132 MPa. Besides, while the vibration force was $850-1650 \mathrm{~N}$, the 


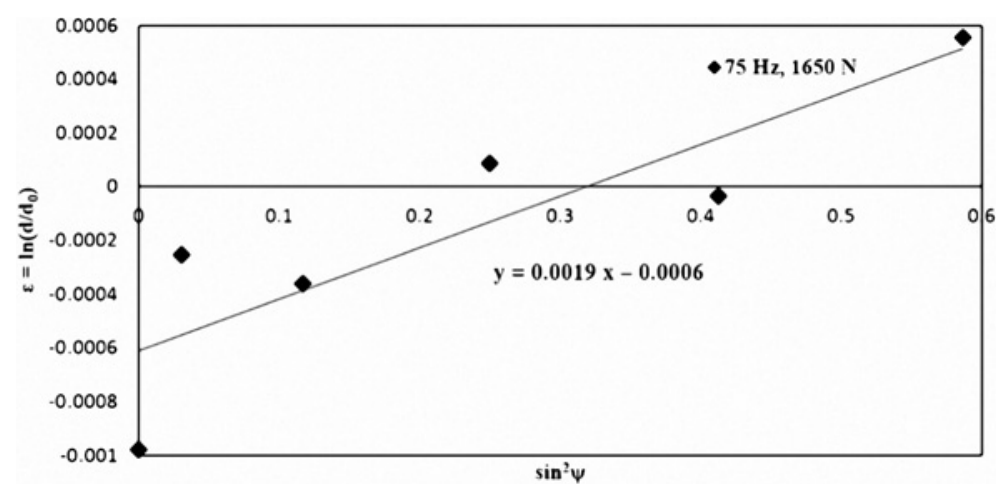

Fig. 5. The $\varepsilon$ versus the $\sin ^{2} \psi$ variation.
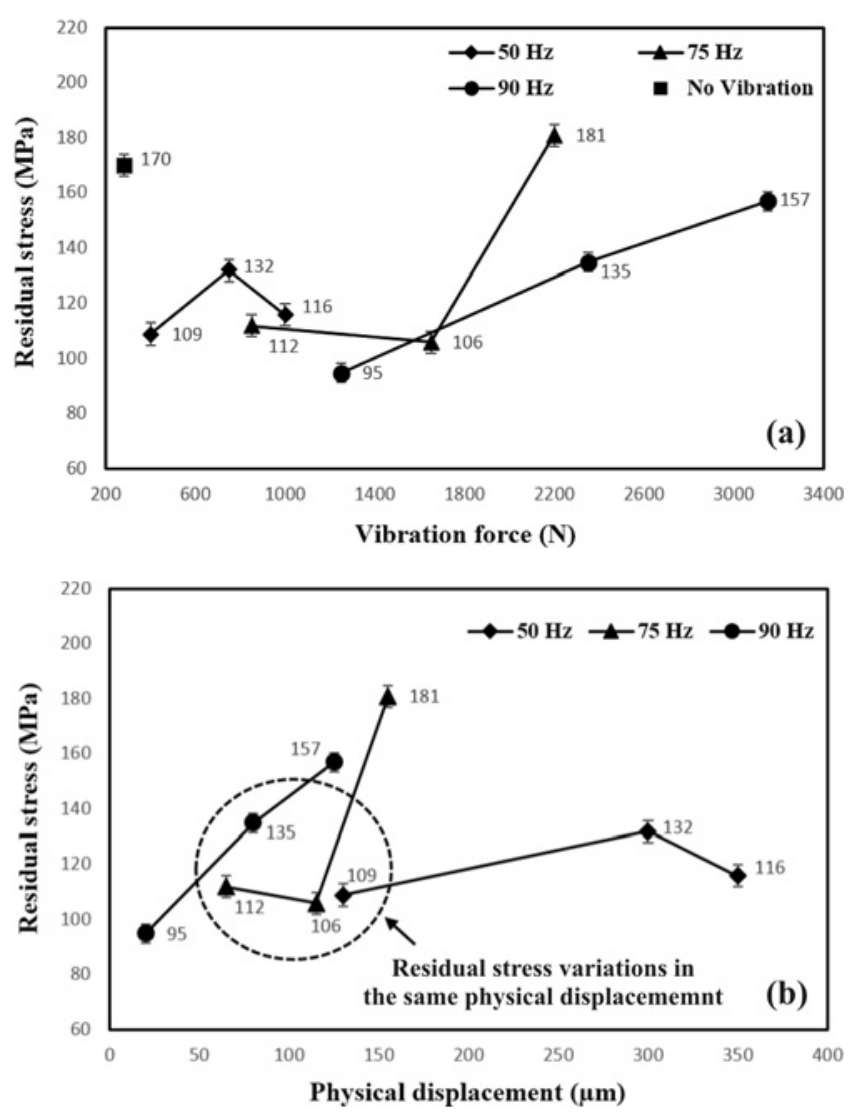

Fig. 6. The residual stress of the welded specimens in terms of (a) vibration force and (b) physical displacement of the structure.

residual stress reduced from 112 to $106 \mathrm{MPa}$. Finally, residual stress increased from $181 \mathrm{MPa}$ when vibration force was $2200 \mathrm{~N}$. Moreover, the increment of the vibration force from $1250-3150 \mathrm{~N}$, at a frequency of $90 \mathrm{~Hz}$, caused the residual stress reduction from 95$157 \mathrm{MPa}$. Compared to the sample which was welded without vibration, the application of vibration during the welding of the samples at a given frequency of 50 , 75 , and $90 \mathrm{~Hz}$ led to residual stress decrement of about 36,38 , and $44 \%$, respectively. Moreover, when the vibration force reached $2200 \mathrm{~N}$, residual stress increased again up to $6.5 \%$, compared to that of sample welded without vibration (Fig. 6a).

From Fig. 6b, another point that can be found is that the residual stress of the specimens welded while being vibrated is affected by the dynamic behavior of the structure. The physical displacement of the structure has a certain amount, which was affected by the vibration force at each given frequency. Therefore, the application of vibration at each frequency not only resulted in the specifically applied vibration force to the structure but also due to the vibrational properties of the structure, caused by changing the physical displacement of the structure at each frequency. The residual stress variations in the physical displacement range of about $130 \mu \mathrm{m}$ are approximately similar for the welded samples. However, the residual stress of the welded specimen at $90 \mathrm{~Hz}$ and the vibration force of $3150 \mathrm{~N}$, although it has a physical displacement in the mentioned range, resulted in an increase in the residual stress of the welded specimen due to the higher vibration force.

It is noted [42] that alternative stress (from mechanical vibration) and residual stress are the principles of vibration stress relief. The purpose of applying vibration to the structure being welded is to introduce the dynamic stress $\left(\sigma_{\mathrm{d}}\right)$ into the structure so that its sum with residual stress $\left(\sigma_{\mathrm{r}}\right)$ exceeds the yield strength $\left(\sigma_{\mathrm{y}}\right)$ of the material and eventually causes some plastic deformation, leads to a reduction in residual stress (Eq. (3)):

$$
\sigma_{\mathrm{d}}+\sigma_{\mathrm{r}} \geq \sigma_{\mathrm{y}}
$$

The reduction of residual stress in the weld is due to plastic deformation around the weld area [43]. Consequently, the decrease in residual stress is a function of the magnitude of the applied vibration force, in which an optimum value of it is required to reduce the amount of residual stress. On the other hand, if the vibration applied on a welded structure is not adequate, the residual stress of the weld cannot be reduced.

As mentioned earlier, when the vibration amplitude increases, the residual stress can be effectively 
removed by simultaneous vibration welding. Meanwhile, higher vibration amplitude influenced the residual stress and might raise it again. Welding produces particularly severe residual stresses, because of large temperature gradients in a short time in the weld metal and surrounding base metal. The interaction between the rapid heating and cooling cycle leads to a heterogeneous strain in non-vibrated weld samples and causes residual stress to form. Due to local heating during welding, complex thermal stresses occur during welding, and residual stress and distortion result after welding. High tensile stresses produced in regions near the weld, while compressive stresses produced in regions away from the weld. This is the usual distribution of residual stresses that remain after welding is completed.

There are two mechanisms for vibration stress relief. The first hypothesis is about the similarity between the vibration stress relief and the heat treatment considering the displacement of atoms that are in the crystalline lattice. By performing low-frequency vibration stress, the atoms are given enough energy to move to a new location. This theory is based on internal friction and is likely for materials that tend to age naturally. The second hypothesis is that stress relief occurs during plastic deformation, in which during VSR, the combination of cyclic applied stresses and residual stresses exceeds the yield strength of the part and causes plastic deformation [44, 45].

\subsection{Fatigue crack growth properties}

To correctly predict the operational life of a component, it is important to understand the physical background of fatigue. One of the primary mechanisms by which metal fatigue occurs is the propagation of small cracks. Cracks can be generated by alternating plastic deformations due to cyclic loads. Even if the applied stress is below the elastic limit, local stress may be higher than the yield stress due to the stress concentration. The first and last stages of fatigue crack growth of the welded samples are shown in Fig. 7. As shown in the picture, the nucleation of the crack was in the weld zone, and it continued to grow along the weld line.

In Fig. 8, fatigue crack lengths are plotted versus the number of cycles leading to failure of the welded specimens. As shown in Fig. 8, the behavior of different welded samples affected by vibration is different from that of the welded specimen without vibration. In other words, at the frequency of $50 \mathrm{~Hz}$, the sample that was welded with the vibration force of $750 \mathrm{~N}$ has better fatigue behavior than that of $1000 \mathrm{~N}$ (Fig. 8a). The variation of fatigue behavior of the material can depend on either the grain size, tensile strength, or residual stress.

At the frequency of $75 \mathrm{~Hz}$, an increase in the vi-
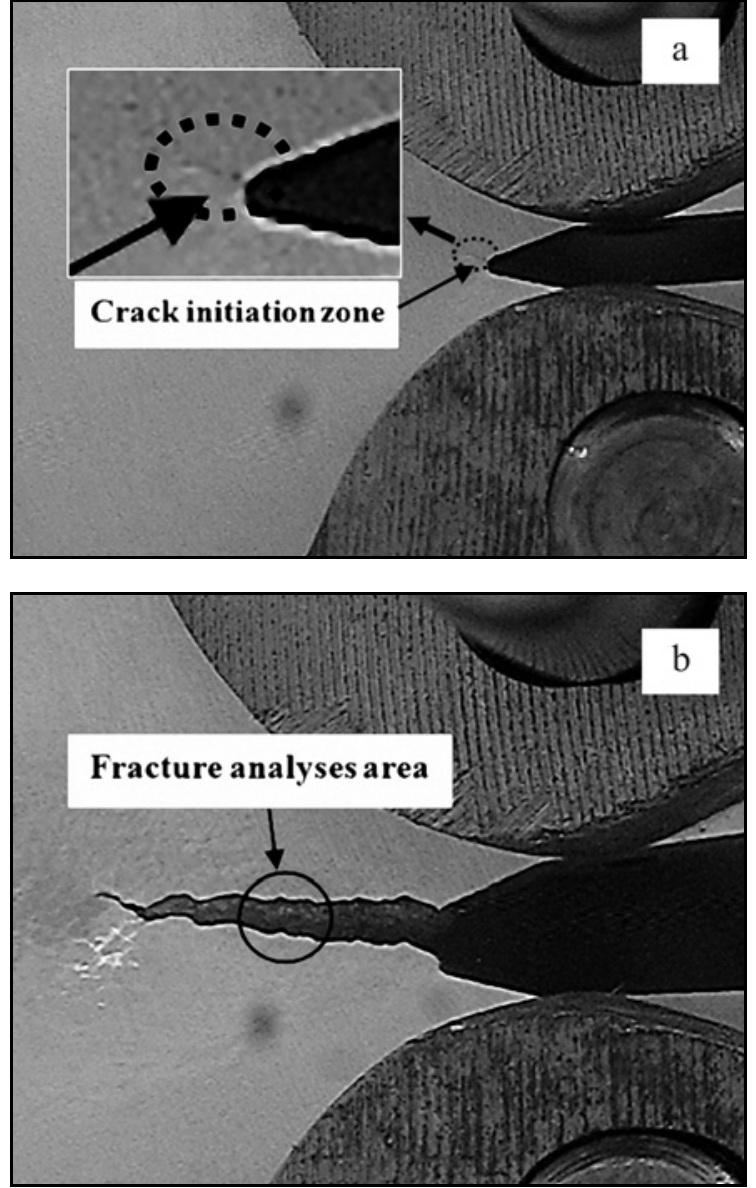

Fig. 7. Fatigue crack growth sample: (a) crack initiation and (b) growth.

bration force resulted in a sharp decrease in fatigue behavior. As shown in Fig. 8b, the fatigue crack behavior of the welded specimen with the vibration force of $1650 \mathrm{~N}$ was much greater than that of $2200 \mathrm{~N}$. On the other hand, the sample welded with the vibration force of $1650 \mathrm{~N}$ failed at higher cycles than the specimen welded while being vibrated with $2200 \mathrm{~N}$. In this frequency range, according to the data obtained from the residual stress examination, the effective factor that causes the various fatigue behavior of the samples is their obvious residual stress difference. The residual stress of the welded specimen with $1650 \mathrm{~N}$ is about $106 \mathrm{MPa}$, while it is about $181 \mathrm{MPa}$ in the welded specimen with $2200 \mathrm{~N}$. Hence, the behavioral differences, which are observed in fatigue crack growth test of these samples, are reasonable.

The fatigue crack growth behavior of the welded specimens at $90 \mathrm{~Hz}$ also confirms the improvement of the fatigue behavior of the welded specimen with the applied vibration force of $1250 \mathrm{~N}$ as compared to the sample welded with $3150 \mathrm{~N}$. In this frequency range, the residual stress of the welded specimen with $3150 \mathrm{~N}$ vibration force is about $157 \mathrm{MPa}$ and is about $95 \mathrm{MPa}$ 

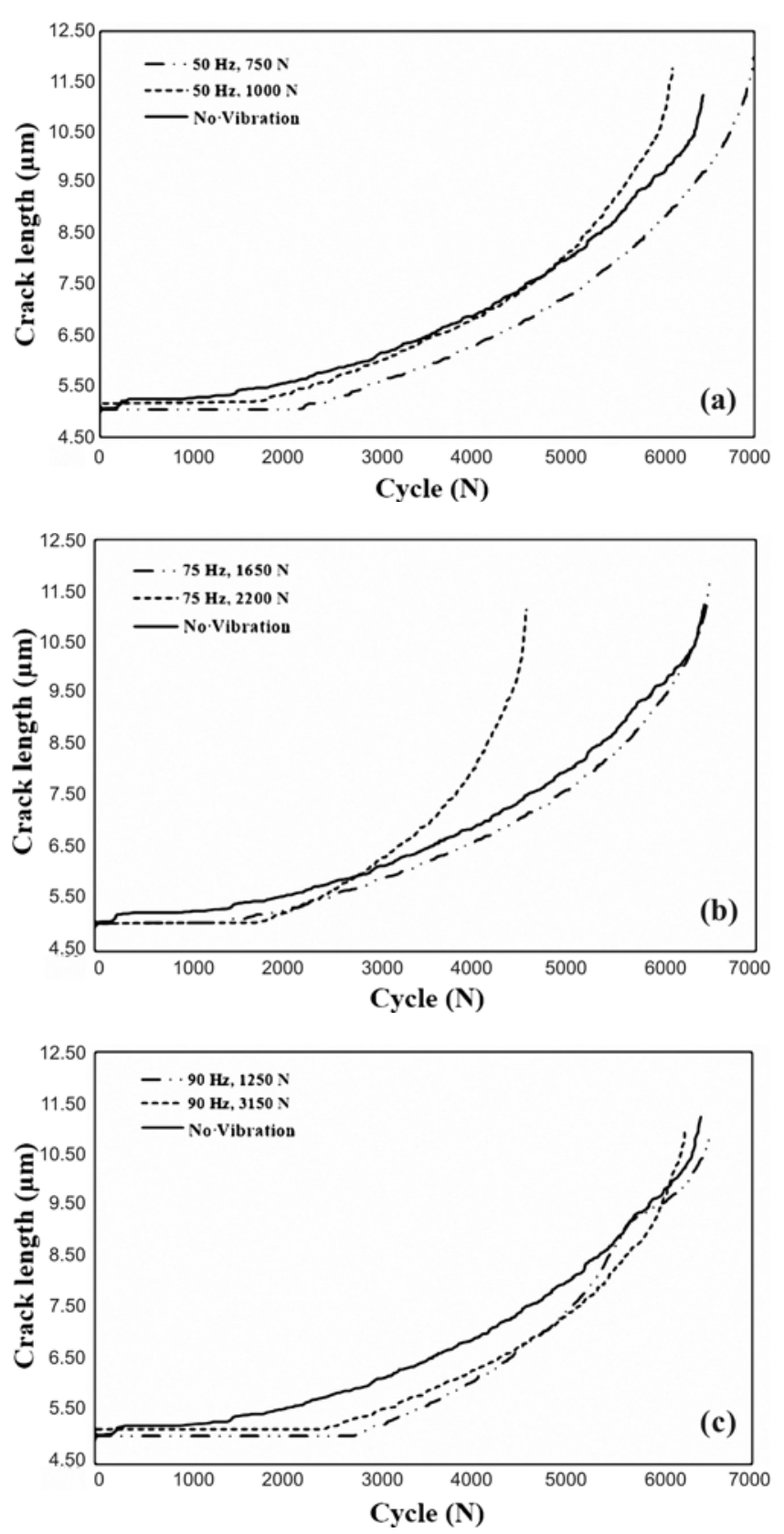

Fig. 8. Fatigue crack growth graphs of the welded specimens during vibration in terms of the number of the cycles to failure, at frequencies of (a) $50 \mathrm{~Hz}$, (b) $75 \mathrm{~Hz}$, and (c) $90 \mathrm{~Hz}$, compared to the no vibration sample.

for the sample that was welded with the vibration force of $1250 \mathrm{~N}$ (Fig. 8c). Finally, the variation that is observed in fatigue crack growth behavior of the welded specimens indicates that the application of mechanical vibration when the sample being welded caused cracks to grow at higher cycles, due to the different residual stress magnitude.

Damage by fatigue usually takes two steps, the appearance of an initial crack, which then grows as a function of the present microstructure and residual stress. Hence, the other distinction that can be seen
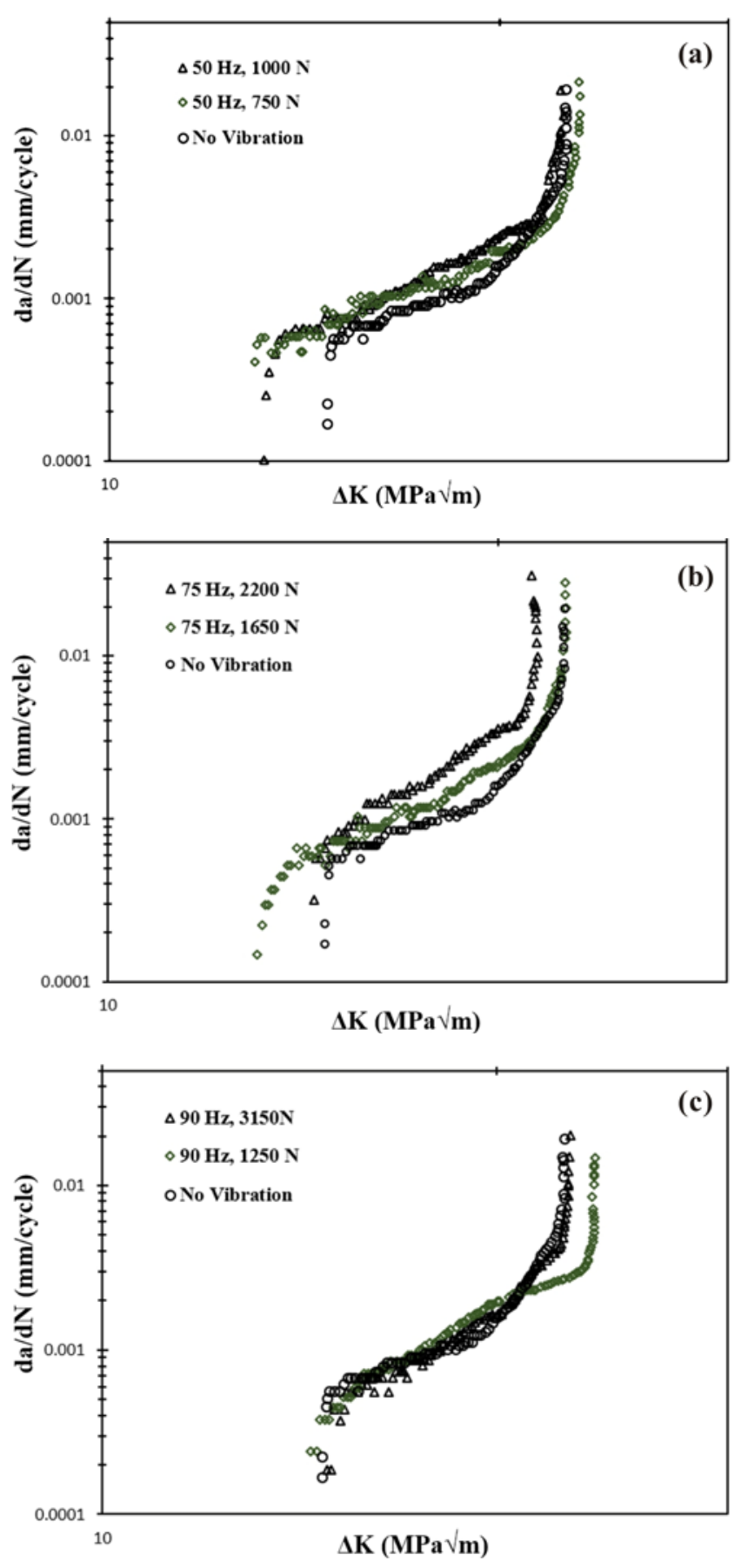

Fig. 9. The crack growth rate of the welded samples versus the stress intensity factor, at frequencies of (a) $50 \mathrm{~Hz}$, (b) $75 \mathrm{~Hz}$, and (c) $90 \mathrm{~Hz}$, compared to the no vibration sample.

from Fig. 8 is the beginning cycles of the crack propagation. Compared to the sample being vibrated during welding, fatigue crack activated at the lower cycles in the sample that was welded without vibration. Moreover, with increasing the vibration force, fatigue crack delayed propagating and crack propagation shifted to the higher cycles.

Figure 9 illustrates the crack growth data of the welded samples with mechanical vibration applied 
Table 6 . The $C$ and $n$ values of the Paris relation

\begin{tabular}{ccccc}
\hline Sample & Frequency $(\mathrm{Hz})$ & Vibration force $(\mathrm{N})$ & $n$ & $C$ \\
\hline 1 & \multirow{2}{*}{50} & 750 & 3.51 & $5.97 \times 10^{-8}$ \\
2 & & 1000 & 4.40 & $5.31 \times 10^{-9}$ \\
\hline \multirow{2}{*}{75} & 1650 & 4.34 & $5.58 \times 10^{-9}$ \\
4 & 2200 & 4.61 & $2.87 \times 10^{-9}$ \\
\hline 5 & \multirow{2}{*}{90} & 1250 & 4.80 & $1.63 \times 10^{-9}$ \\
6 & & 3150 & 3.80 & $2.21 \times 10^{-8}$ \\
\hline 7 & \multirow{2}{*}{ Without vibration } & 4.40 & $2.98 \times 10^{-9}$ \\
\hline
\end{tabular}

compared to the samples without vibration. The crack propagation life is estimated through the observed dependence of the crack growth rate, $\mathrm{d} a / \mathrm{d} N$, on the range of the stress intensity factor, $\Delta K$. With studying the crack growth rate chart based on variations in the stress intensity factor, it is possible to investigate the effect of vibration during welding on the fatigue crack growth rate. It can be seen from Fig. 9 that vibration during welding is an effective parameter that affects the fatigue curves. At low $\Delta K$ values, the crack growth rate is low in all welded specimens and is approximately similar to the crack growth rate of the welded specimen without vibration. At the $50 \mathrm{~Hz}$ frequency range at the beginning of crack growth, both samples (welded with the vibration force of 750 and $1000 \mathrm{~N}$ ) have low crack growth rates. Their crack growth rate is somewhat close to that of the sample welded without vibration. However, at higher $\Delta K$ values, it can be said that the fatigue growth rate of the specimen welded with the vibration force of $750 \mathrm{~N}$ is lower than the no vibration welded sample. Moreover, the fatigue crack growth rate of the sample welded while being vibrated with $1000 \mathrm{~N}$ is approximately similar to the sample welded without vibration.

In the frequency range of $75 \mathrm{~Hz}$ and the vibration forces of 1650 and $2200 \mathrm{~N}$, they also exhibited similar behavior to those described for welded samples at $50 \mathrm{~Hz}$, at low $\Delta K$ values. On the other hand, at low $\Delta K$, the fatigue crack growth rate in these specimens is approximately similar to that of the vibrationfree welded specimen. However, by increasing $\Delta K$ to higher values, the crack growth rate of the welded specimen under the vibration force of $1650 \mathrm{~N}$ is close to that of the non-vibrating weld specimen, and the fatigue crack growth rate of the sample that was welded while being vibrated with $2200 \mathrm{~N}$ vibration force, is higher. As mentioned earlier, the welded specimen at $2200 \mathrm{~N}$ has the highest residual stress compared to the other specimens, and as a result, such behavior (higher crack growth rate) is expected.

The fatigue crack growth behavior of the $90 \mathrm{~Hz}$ welded specimens indicates that at this frequency range, at low $\Delta K$, the lower fatigue crack growth rate of the sample being vibrated during welding was observed as the same as that of the sample that was welded without vibration. By increasing $\Delta K$ to higher values, the crack growth rate of the sample welded with $1250 \mathrm{~N}$ is even lower than that of the welded sample with no vibration. Additionally, the crack growth rate of the sample welded with the vibration force of $3150 \mathrm{~N}$ was also lower than that of the sample welded without vibration. As previously discussed, the welded specimen with the vibration force of $1250 \mathrm{~N}$ has the lowest residual stress compared to that of all the welded specimens studied and it is reasonable to have lower fatigue crack growth rate. Several models based on the principles of fracture mechanics for the prediction of fatigue crack growth in components under dynamic loads have been proposed, the best known to be the Paris law (Eq. (4)), where $\mathrm{d} a / \mathrm{d} N$ is the crack growth rate per cycle $\left(\mathrm{mm} \mathrm{cycle}^{-1}\right), \Delta K$ is the stress intensity factor $(\mathrm{MPa} \sqrt{\mathrm{mm}}), C$ and $n$ are the constants [46]:

$$
\frac{\mathrm{d} a}{\mathrm{~d} n}=C(\Delta K)^{n}
$$

Table 6 shows the $C$ and $n$ values of the Paris relation obtained from the crack growth rate test.

The fracture surfaces of the fatigue crack growth test specimens are shown in Fig. 10. According to Fig. 10, the fracture surface is composed of three regions. The crack initiation zone exhibited a relatively smooth microstructure. The crack propagation zone (marked as fracture analyses area) had prominent striation marks with a river-like appearance. The presence of these patterns confirms fatigue failure (the SEM micrographs). The final failure zone of fatigue is the ultimate damage (crack growth end) caused by void nucleation, coalescence, and crack growth, showing a rough and fine dimple structure. According to Fig. 10, the microcracks are visible in some of the sections investigated. The presence of micro-cracks increases the crack growth path and thus increases the material's fatigue life. Crack nucleation and growth occur due to some microstructural defects. 

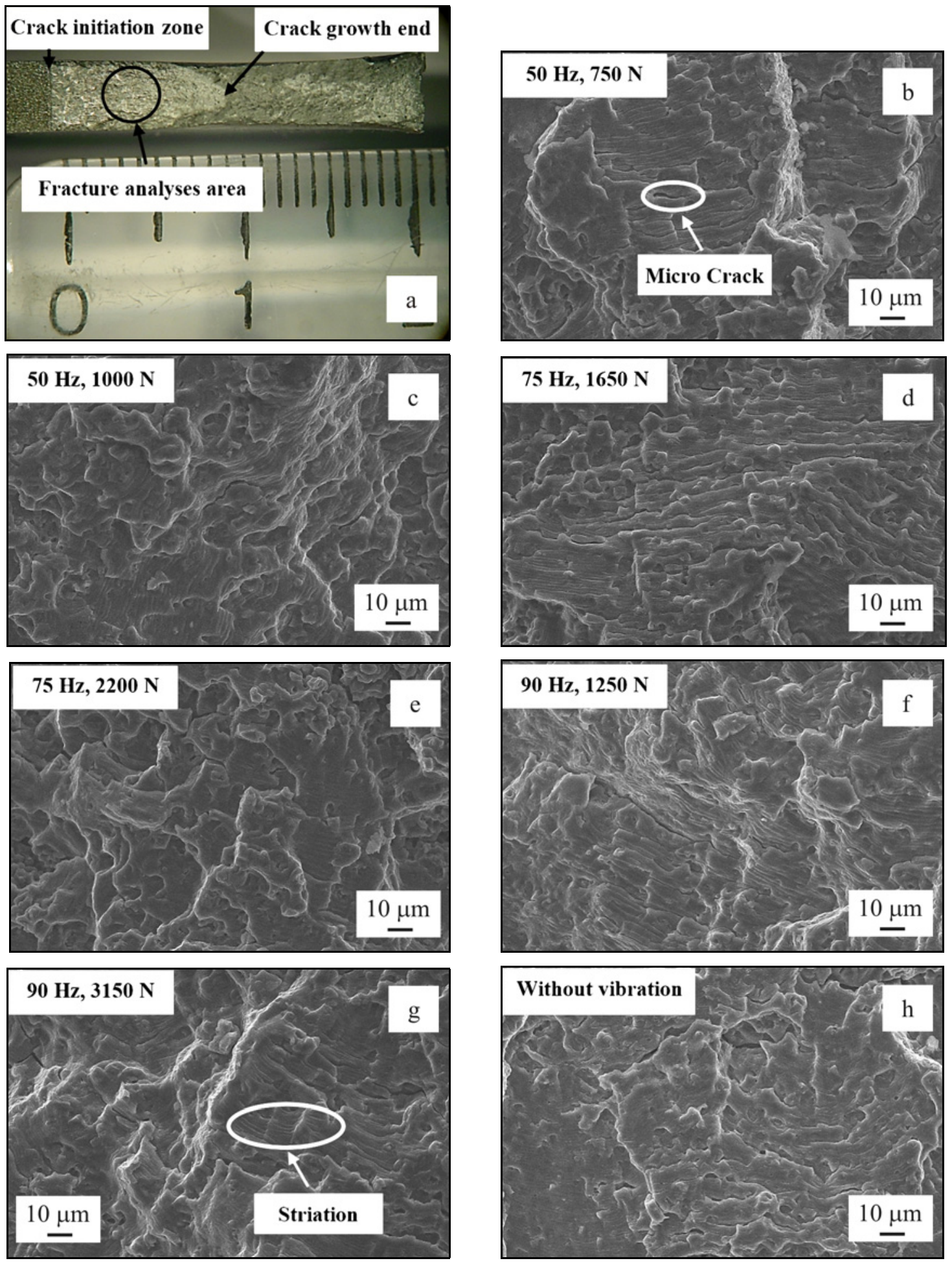

Fig. 10. The fracture surface of the fatigue cracks growth samples: (a) macroscale, (b) $50 \mathrm{~Hz}, 750 \mathrm{~N}$, (c) $50 \mathrm{~Hz}, 1000 \mathrm{~N}$, (d) $75 \mathrm{~Hz}, 1650 \mathrm{~N}$, (e) $75 \mathrm{~Hz}, 2200 \mathrm{~N}$, (f) $90 \mathrm{~Hz}, 1250 \mathrm{~N}$, (g) $90 \mathrm{~Hz}, 3150 \mathrm{~N}$, and (h) without vibration.

However, as mentioned earlier, the residual stress, which was generated in the weld zone (i.e., due to non-homogeneous heating and cooling cycles, from the fusion welding process), is an effective factor in changing the behavior of the material against fatigue crack growth rate. According to the report [47], the resid- ual compressive stress in the weld zone reduces the stress intensity factor at the crack tip. Similarly, at lower values of $\Delta K$, the crack growth rate decreases, and as $\Delta K$ increases, the positive effect of residual compressive stress on crack growth decreases. Therefore, at higher $\Delta K$ values, the crack growth rate of 
the welded specimen increases [48].

According to the aforementioned, residual stress in the non-vibrating welded samples as well as the samples welded while being vibrated, is tensile residual stress, which decreased due to the application of vibration during welding. The presence of residual tensile stress has a detrimental effect on the growth rate of fatigue cracks. In other words, the tensile residual stress magnitude has a serious impact on fatigue life, so, as the tensile residual stress is higher, the lower fatigue life is expectable.

\section{Conclusions}

1. The sample welded with conventional GMAW includes columnar grains in the fusion line and the coarse equiaxed grain in the weld center. However, under the influence of mechanical vibrations applied during the welding process, the columnar structure was replaced by fine equiaxed grains. As the vibration force increased, the area fraction of the equiaxed grains extended even to $75 \%$.

2. Residual stress decreased due to the application of vibration during welding. Compared to the sample that was welded without vibration, the application of vibration during the welding of the samples at given frequencies of 50,75 , and $90 \mathrm{~Hz}$ led to residual stress decrement of about 36,38 , and $44 \%$, respectively.

3. At low $\Delta K$, the crack growth rate is low in all welded specimens and is approximately similar to the crack growth rate of the sample welded with conventional GMAW. However, at high $\Delta K$, the crack growth rate of the samples changed significantly due to the effect of residual stress.

4. The residual stress in the welded sample is an effective factor that affects the growth rate of fatigue cracks in the material. It is essential to know what kind of residual stress generated in the welded samples. The compressive residual stress in the weld zone reduces the stress intensity factor at the crack tip and improves fatigue life, while the tensile residual stress seriously reduces the fatigue life of the material.

5. According to the fracture analysis results, the microcracks are visible in some of the sections investigated. The presence of these microcracks increases the crack growth path and thus increases the material's fatigue life.

\section{References}

[1] G. Mathers, The welding of aluminum and its alloys, Woodhead Publishing Limited, New York, 2002.

[2] T. Anderson, Understanding aluminum alloys, Weld. J. 81 (2002) 77-80.
[3] G. E. Totten, D. S. MacKenzie, Handbook of aluminum: Vol. 1: Physical metallurgy and processes, CRC Press, New York, 2003. ISBN 0-8247-0494-0.

[4] J. R. Kissell, R. L. Ferry, Aluminum structures: A guide to their specifications and design, 2nd ed., John Wiley \& Sons, Inc., New York, 2002. ISBN 0-471$-01965-8$.

[5] T. Sheppard, N. Raghunathan, Modification of cast structures in $\mathrm{Al}-\mathrm{Mg}$ alloys by thermal treatments, Mater. Sci. Technol. 5 (1989) 268-280. doi:10.1179/mst.1989.5.3.268

[6] L. Huang, X. Hua, D. Wu, Z. Jiang, F. Li, H. Wang, S. Shi, Microstructural characterization of 5083 aluminum alloy thick plates welded with GMAW and twin wire GMAW processes, Int. J. Adv. Manuf. Tech. 93 (2017) 1809-1817. doi:10.1007/s00170-017-0480-1

[7] J. Xu, L. Chen, C. Ni, Effect of vibratory weld conditioning on the residual stresses and distortion in multipass girth-butt welded pipes, Int. J. Press. Vessels Pip. 84 (2007) 298-303. doi:10.1016/i.ijpvp.2006.11.004

[8] Q. Lu, L. Chen, C. Ni, Improving welded valve quality by vibratory weld conditioning, Mater. Sci. Eng. A 457 (2007) 246-253. doi:10.1016/i.msea.2006.12.120

[9] W. Wu, D. Y. Lin, S. H. Chen, Mechanical properties of weldment affected by various vibration frequencies, J. Mater. Sci. Lett. 18 (1999) 1829-1831. doi:10.1023/A:1006647222302

[10] W. Jiang, Y. Zhang, W. Woo, Using heat sink technology to decrease residual stress in $316 \mathrm{~L}$ stainless steel welding joint: Finite element simulation, Int. J. Press. Vessels Pip. 92 (2012) 56-62. doi:10.1016/j.ijpvp.2012.01.002

[11] M. James, D. Hughes, Z. Chen, H. Lombard, D. Hattingh, D. Asquith, J. R. Yates, P. J. Webster, Residual stresses and fatigue performance, Eng. Fail. Ana. 14 (2007) 384-395. doi:10.1016/j.engfailanal.2006.02.011

[12] V. E. Blashchuk, I. B. Lavrovskaya, L. M. Onoprienko, G. M. Shelenkov, V. E. Troyanovskii, Reduction of residual stresses in welded joints in titanium alloys, Chem. Pet. Eng. 27 (1991) 715-719. doi:10.1007/BF01155443

[13] T. Sun, Z. Wang, J. Li, T. Zhang, Effect of ultrasonic vibration solidification treatment on the corrosion behavior of AZ80 magnesium alloy, Int. J. Electrochem. Sci. 8 (2013) 7298-7319.

[14] J. Hou, T. Shoji, Z. P. Lu, Q. T. Peng, J. Q. Wang, E. H. Han, W. Ke, Residual strain measurement and grain boundary characterization in the heataffected zone of a weld joint between Alloy 690TT and Alloy 52, J. Nucl. Mater. 397 (2010) 109-115. doi:10.1016/j.jnucmat.2009.12.016

[15] F. Sarsilmaz, U. Çaydaş, Statistical analysis on mechanical properties of friction-stir-welded AA 1050/AA 5083 couples, Int. J. Adv. Manuf. Technol. 43 (2009) 248-255. doi:10.1007/s00170-008-1716-x

[16] S. Amini, M. R. Amiri, A. Barani, Investigation of the effect of tool geometry on friction stir welding of 5083-O aluminum alloy, Int. J. Adv. Manuf. Technol. 76 (2015) 255-261. doi:10.1007/s00170-014-6277-6

[17] I. Kalemba-Rec, M. Kopyściański, D. Miara, K. Krasnowski, Effect of process parameters on mechanical properties of friction stir welded dissimilar 7075-T651 and 5083-H111 aluminum alloys, Int. J. Adv. Manuf. Technol. 97 (2018) 2767-2779. doi:10.1007/s00170-018-2147-y 
[18] A. S. Munsi, A. J. Waddell, C. A. Walker, The effect of vibratory stress on the welding microstructure and residual stress distribution, Proc. Inst. Mech. Eng. Part L: J. Mater. Des. Appl. 215 (2001) 99-111. doi:10.1177/146442070121500204

[19] D. Djuric, R. Vallant, K. Kerschbaumer, N. Enzinger, Vibration stress relief treatment of welded highstrength martensitic steel, Weld. World 55 (2011) 8693. doi:10.1007/BF03263519

[20] C. W. Kuo, C. M. Lin, G. H. Lai, Y. C. Chen, Y. T. Chang, W. Wu, Characterization and mechanism of 304 stainless steel vibration welding, Mater. Trans. 48 (2007) 2319-2323. doi:10.2320/matertrans.MB200706

[21] C. C. Hsieh, C. H. Lai, W. Wu, Effect of vibration on microstructures and mechanical properties of 304 stainless steel GTA welds, Met. Mater. Int. 19 (2013) 835-844. doi:10.1007/s12540-013-4026-2

[22] G. I. Eskin, Ultrasonic treatment of light alloy melts, 2nd ed., CRC Press, New York, 1998. ISBN 9781138075979 .

[23] J. Campbell, Effects of vibration during solidification, Int. Met. Rev. 26 (2013) 71-108. doi:10.1179/imtr.1981.26.1.71

[24] A. S. Munsi, A. J. Waddell, C. A. Walker, Modification of welding stresses by flexural vibration during welding, Sci. Tech. Weld. Join. 6 (2001) 133-138. doi:10.1179/136217101101538668

[25] C. A. Walker, A. J. Waddell, D. J. Johnston, Vibratory stress relief - an investigation of the underlying processes, Proc. Inst. Mech. Eng. Part E: J. Proc. Mech. Eng. 209 (1995) 51-58. doi:10.1243/PIME_PROC_1995_209_228_02

[26] G. C. Luh, R. M. Hwang, Evaluating the effectiveness of vibratory stress relief by a modified hole-drilling method, Int. J. Adv. Manuf. Technol. 14 (1998) 815823. doi:10.1007/BF01350766

[27] S. P. Tewari, A. Shanker, Microstructural changes associated with vibratory prepared weldments, J. Mater. Sci. Lett. 12 (1993) 1335-1336. doi:10.1007/BF00241699

[28] P. K. Singh, D. Patel, B. Prasad, Development of vibratory welding technique and tensile properties investigation of shielded metal arc welded joints, Indian J. Sci. Tech. 9 (2016) 1-6. doi:10.17485/ijst/2016/v9i35/92846

[29] M. V. Rao, P. S. Rao, B. S. Babu, Investigation of the influence of mechanical vibrations on the hardness of Al5052 weldments, Indian J. Sci. Tech. 9 (2016) 1-4. doi:10.17485/ijst/2016/v9i39/95587

[30] M. V. Rao, P. S. Rao, B. S. Babu, Effect of vibratory tungsten inert gas welding on tensile strength of aluminum 5052-H32 alloy weldments, Mater. Focus 6 (2017) 325-330. doi:10.1166/mat.2017.1415

[31] R. Tamasgavabari, A. R. Ebrahimi, S. M. Abbasi, A. R. Yazdipour, The effect of harmonic vibration with a frequency below the resonant range on the mechanical properties of AA-5083-H321 aluminum alloy GMAW welded parts, Mater. Sci. Eng. A 736 (2018) 248-257. doi:10.1016/j.msea.2018.08.106

[32] R. Tamasgavabari, A. R. Ebrahimi, S. M. Abbasi, A. R. Yazdipour, Effect of harmonic vibration during gas metal arc welding of AA-5083 aluminum alloy on the formation and distribution of intermetallic compounds, J. Manuf. Proc. 49 (2020) 413-422. doi:10.1016/j.jmapro.2019.12.003
[33] BS EN 15305 Non-destructive testing, Test method for residual stress analysis by X-ray diffraction, BSI, 2008.

[34] ASTM E647, Standard test method for measurement of fatigue crack growth rates, ASTM International, 2003.

[35] G. J. Ram, T. K. Mitra, M. K. Raju, S. Sundaresan, Use of inoculants to refine weld solidification structure and improve weldability in type 2090 Al-Li alloy, Mater. Sci. Eng. A 276 (2000) 48-57. doi:10.1016/S0921-5093(99)00515-8

[36] V. G. Davydov, T. D. Rostova, V. V. Zakharov, Y. A. Filatov, V. I. Yelagin, Scientific principles of making an alloying addition of scandium to aluminum alloys, Mater. Sci. Eng. A 280 (2000) 30-36. doi:10.1016/S0921-5093(99)00652-8

[37] A. F. Norman, K. Hyde, F. Costello, S. Thompson, S. Birley, P. B. Prangnell, Examination of the effect of Sc on 2000 and 7000 series aluminum alloy castings: for improvements in fusion welding, Mater. Sci. Eng. A $354(2003)$ 188-198. doi:10.1016/S0921-5093(02)00942-5

[38] S. Kou, Welding Metallurgy, 2nd ed., John Wiley \& Sons, Inc., New Jersey, 2003. doi:10.1002/0471434027

[39] J. G. Wylde, Proposed investigation of process for reducing residual welding stresses and distortion by vibration, Mechanical relaxation of residual stresses, ASTM International, Materials Park, 1988.

[40] M. P. Berezhnyts'ka, Methods for determining residual welding stresses and their relief (A review), Mater. Sci. 37 (2001) 933-939. doi:10.1023/A:1015601525897

[41] M. Koc, J. Culp, T. Altan, Prediction of residual stresses in quenched aluminum blocks and their reduction through cold working processes, J. Mater. Proc. Tech. 174 (2006) 342-354. doi:10.1016/j.jmatprotec.2006.02.007

[42] P. Schempp, C. E. Cross, R. Häcker, A. Pittner, M. Rethmeier, Influence of grain size on mechanical properties of aluminum GTA weld metal, Weld. World 57 (2013) 293-304. doi:10.1007/s40194-013-0026-6

[43] Y. Yang, Understanding of vibration stress relief with computation modeling, J. Mater. Eng. Perform. 18 (2009) 856-862. doi:10.1007/s11665-008-9310-9

[44] M. Easton, D. Stjohn, Grain refinement of aluminum alloys: Part I. The nucleant and solute paradigms a review of the literature, Metal. Mater. Trans. A 30 (1999) 1613-1623. doi:10.1007/s11661-999-0098-5

[45] G. P. Wozney, G. R. Crawmer, An investigation of vibrational stress relief in steel, Weld. J. 47 (1968) 411-419.

[46] P. C. Paris, A rational analytic theory of fatigue, The Trend in Engineering 13 (1961) 9-14.

[47] R. John, K. V. Jata, K. Sadananda, Residual stress effects on near-threshold fatigue crack growth in friction stir welds in aerospace alloys, Int. J. Fatigue 25 (2003) 939-948. doi:10.1016/j.ijfatigue.2003.08.002

[48] M. N. James, D. G. Hattingh, D. J. Hughes, L. W. Wei, E. A. Patterson, J. Q. Da Fonseca, Synchrotron diffraction investigation of the distribution and influence of residual stresses in fatigue, Fatigue Frac. Eng. M. 27 (2004) 609-622. doi:10.1111/i.1460-2695.2004.00789.x 